\title{
Possible Role of AMPK/SIRT1 Signaling on Energy Balance in Geniposide- Treated INS-1 Cells
}

\author{
Lixia Guo ${ }^{1}$, Chunyan Liu², Fei Yin ${ }^{1,2}$ and Jianhui Liü ${ }^{1,2 *}$ \\ ${ }^{1}$ Chongqing Key Lab of Catalysis and Functional Organic Molecules, Chongqing Technology and Business University, Chongqing, PR China \\ ${ }^{2}$ College of Pharmacy and Bioengineering, Chongqing University of Technology, Chongqing, PR China
}

\begin{abstract}
Our previous work showed that in pancreatic INS-1 cells, geniposide exerted a contrary role on both glucosestimulated insulin secretion (GSIS) and glucose uptake and metabolism in the presence of low and high glucose. But the molecular mechanisms are presently not well understood. In the present study, we design to probe the role of AMP-activated protein kinase (AMPK) and NAD+- dependent deacetylase sirtuin-1 (SIRT1) on geniposide regulating GSIS, and analyze the interaction between AMPK and SIRT1 in pancreatic $\beta$ cells. Our results indicate that geniposide induce the phosphorylation of AMPK and enhance the expression of SIRT1 in the presence of low concentration of glucose, but in the presence of high concentrations of glucose, geniposide played a contrary role on those. Furthermore, Compound C (an AMPK inhibitor) and Ex527 (a potent and selective inhibitor of SIRT1) prevent the effects of geniposide on glucose uptake, ATP production and GSIS in INS-1 cells. Taken together, our findings suggest that AMPK/SIRT1 are associated with the role of geniposide on energy balance in INS-1 cells.
\end{abstract}

Keywords: AMP-activated protein kinase (AMPK); Geniposide; Glucose stimulating insulin secretion (GSIS); $\mathrm{NAD}^{+}$- dependent deacetylase sirtuin-1 (SIRT1)

\section{Introduction}

AMP-activated protein kinase (AMPK), known as a "metabolic master switch", is one of the essential players in cellular energy regulation adapting cellular demands to nutritional and metabolic variations [1]. Usually, in pancreatic $\beta$ cells, nutrient uptake and glucose metabolism increases the ratio of ATP/ADP leading to closure of the $\mathrm{K}^{+} / \mathrm{ATP}$ channel. Accumulation of $\mathrm{K}^{+}$inside the cell leads to membrane depolarization that in turn opens voltage-sensitive calcium channels and calcium ion influx. Calcium triggers exocytosis of the readily releasable pool of insulin granules docked at the plasma membrane resulting insulin secretion [2]. In this process, AMPK may control several of these events to regulate insulin secretion, in especial including glucose metabolism. Activation of AMPK results in the inhibition of energyconsuming pathways and activation of ATP-producing pathways $[3,4]$. So, pharmacological stimulation of the enzyme exerts pleiotropic beneficial effects on metabolic homeostasis including muscle glucose uptake, fatty acid oxidation, decrease of hepatic gluconeogenesis, inhibition of lipolysis and lowering of triglyceride concentration [5].

Furthermore, the increasing data shows that AMPK and s NAD ${ }^{+}$ dependent deacetylase sirtuin-1 (SIRT1) can activate each other, which raises the possibility that they are components of a cycle [6-8]. SIRT1 is widely expressed in mammalian tissues $[9,10]$, including pancreas ( $\beta$ cells), liver, skeletal muscle, adipose tissue, brain, and endothelium, and it is an $\mathrm{NAD}^{+}$-dependent histone/protein deacetylase whose activity is also regulated by nutrient. A change in energy state or activation of AMPK leads to activation of SIRT1, perhaps by increasing NAD ${ }^{+}$ or the NAD/NADH ratio [7] and/or the activity of Nampt [8]. SIRT1 then deacetylates and activates LKB1, which in turn activates AMPK. Glucose metabolism and calorie regulation by AMPK/SIRT1 sensing network have been shown to improve insulin sensitivity [2], decrease ectopic lipid deposition $[11,12]$, and prevent pancreatic $\beta$-cell damage [13]. So, AMPK/SIRT1 have emerged as an new target to treat metabolic diseases such as type 2 diabetes and obesity [14,15].

Our previous studies have shown that geniposide enhanced glucose stimulated insulin secretion (GSIS) in the presence of low or moderately high concentrations of glucose in pancreatic $\beta$ cells $[16,17]$. However, geniposide exerted an acute inhibitory effect on GSIS when the cells were challenged with a high concentration of glucose (over $25 \mathrm{mM}$ ). We also observed that, the effects of geniposide on GSIS were associated with glucose uptake and metabolism by regulating the expression of pyruvate carboxylase [17]. These are intriguing results suggest a potential role of geniposide in regulating GSIS, at least in part, was a result of glucose metabolism, which was a key process for insulin release. However, the mechanisms of geniposide regulating glucose uptake and metabolism in INS-1 cells need to be further investigated.

Mounting evidence shows that AMPK/SIRT1 are the key players of glucose metabolism [18-20]. In the present study, beside to probe the role of AMPK/ SIRT1 on geniposide regulating GSIS in pancreatic $\beta$ cells, Compound C, a specific AMPK inhibitor, and Ex 527, a specific SIRT1 inhibitor, were used to explore the role of AMPK and SIRT1 on geniposide regulating GSIS in pancreatic $\beta$ cells.

\section{Materials and Methods}

\section{Materials}

“Compound C" (6-[4-(2-piperidin-1-yletoxy)-phenyl)]-3pyridin-4-yl-pyrrazolo [1,5-a]pyrimidine), an AMPK inhibitor, and Ex 527, a potent and selective SIRT1 inhibitor, were purchased from Sigma-Aldrich (St Louis, MO, USA). Rat/Mouse insulin ELISA kit was obtained from Millipore Corporation (Billerica, MA, USA). Specific antibodies against phospho-AMPK, AMPKa1/2, SIRT1, and antimouse and anti-rabbit HRP-conjugated antibodies were purchased from Cell Signaling Technology (Danvers, MA, USA).

*Corresponding author: Prof. Jianhui Liu, College of Pharmacy and Bioengineering, Chongqing University of Technology, Chongqing, 400054, PR China, Tel: 862362563190; E-mail: jhliu@cqut.edu.cn

Received January 11, 2016; Accepted January 20, 2016; Published January 25 , 2016

Citation: Guo L, Liu C, Yin F, Liu J (2016) Possible Role of AMPK/SIRT1 Signaling on Energy Balance in Geniposide-Treated INS-1 Cells. Med chem 6: 033-038. doi:10.4172/2161-0444.1000319

Copyright: (c) 2016 Guo L, et al. This is an open-access article distributed under the terms of the Creative Commons Attribution License, which permits unrestricted use, distribution, and reproduction in any medium, provided the original author and source are credited. 


\section{Cell culture}

INS- 1 cells, a rat pancreatic $\beta$-cell line, was purchased from CCTCC (China Center for Type Culture Collection). The cells were cultured in RPMI medium 1640 with $11 \mathrm{mM}$ glucose and supplemented with $10 \%$ fetal bovine serum (FBS), $10 \mathrm{mM}$ HEPES, $100 \mathrm{U} / \mathrm{ml}$ penicillin, $100 \mu \mathrm{g} /$ $\mathrm{ml}$ streptomycin, $2 \mathrm{mM}$ Lglutamine, $1 \mathrm{mM}$ sodium pyruvate and $50 \mu \mathrm{M}$ mercaptoethanol under $5 \% \mathrm{CO}_{2}$ and $95 \%$ air at $37^{\circ} \mathrm{C}$.

\section{Assay of glucose uptake and ATP level}

To determine the effect of geniposide on glucose uptake and metabolism, INS- 1 cells were seeded onto 6-well plates. After overnight incubation, the cells were washed once with KRBB and starved for 2 hours in KRBH buffer. And then, an AMPK inhibitor Compound C, or a SIRT1 inhibitor Ex 527 were added respectively in the presence or absence of $10 \mu \mathrm{M}$ geniposide with KRBB containing 5.5 or $33 \mathrm{mM}$ of glucose. After incubated for 20 minutes, the buffer was collected for the measurement of glucose concentration, which was used to calculate glucose uptake as reported previously 17 . The cell lysates were used to determine ATP content. Glucose concentration in the buffer was measured using a glucose assay kit according to protocol supplied by the manufacturer (Bioversion, Mountain View, CA). The content of ATP in cell lysates was measured using ATP bioluminescence assay kits according to the manufacturer's instructions (Roche, Mannheim, Germany).

\section{Immunoblotting}

After treated with geniposide in the presence of different concentrations of glucose, INS-1 cells were washed with cold PBS and lysed in a lysis buffer containing $20 \mathrm{mM}$ Tris- $\mathrm{HCl}(\mathrm{pH} 7.5)$, $150 \mathrm{mM} \mathrm{NaCl}, 1 \mathrm{mM}$ EDTA, $1 \%$ (v/v) Triton X-100, 0.1\% sodium dodecyl sulfate, protease inhibitors (aprotinin, $30 \mu \mathrm{g} / \mathrm{ml}$; leupeptin, $4 \mu \mathrm{g} / \mathrm{ml}$; pepstatin, $2 \mu \mathrm{g} / \mathrm{ml}$; and phenylmethyl sulfonyl fluoride, 10 $\mu \mathrm{g} / \mathrm{ml}), 1 \mathrm{mM} \mathrm{Na}_{3} \mathrm{VO}_{4}$, and $2.5 \mathrm{mM} \mathrm{Na}_{4} \mathrm{P}_{2} \mathrm{O}_{7}$. Lysates were sonicated for approximately $10 \mathrm{~s}$, protein concentrations were determined by a BCA protein assay kit (Beyotime, Shanghai, China). The samples were stored at $-80^{\circ} \mathrm{C}$ until use. An aliquot of $10-20 \mu \mathrm{g}$ protein from each cell extract was loaded on a $10 \%$ SDS-PAGE gel. After electrophoretic separation, proteins were transferred to polyvinylidene difluoride (PVDF) membrane. Primary and secondary antibodies were diluted in a blocking solution and incubated with the membrane for indicated times as described previously [21]. Excess antibody was washed off with $20 \mathrm{mM}$ Tris-buffered saline containing Tween-20 (TBST, $20 \mathrm{mM}$ Tris, $150 \mathrm{mM} \mathrm{NaCl}$ and $0.1 \%$ Tween 20; pH 7.5). Immunoreactivity was detected using enhanced chemiluminescence (ECL) western blotting kit (Amersham Pharmacia Biotech AB, Uppsala, Sweden). Bands were analyzed by densitometric scanning using the Quantity One software (Bio-Rad, Hercules, CA, USA).

\section{Statistical analysis}

All statistical analyses were conducted using the software of Origin version 8.0 (OriginLab Corporation, MA). Data were analyzed using one-way ANOVA followed with the Tukey's post-doc test or twoway ANOVA followed with the Bonferroni's post-hoc test for the differences among the treatment means, where $\mathrm{P}<0.05$ was considered significant. Results are presented as means \pm SD from at least three times experiments.

\section{Results}

\section{Effects of geniposide on the phosphorylation of AMPK and the expression of SIRT1}

In this study, we determined the effect of geniposide on the phosphorylations of AMPK and the expression of SIRT1 in the presence of low $(5.5 \mathrm{mM})$ and high $(33 \mathrm{mM})$ concentrations of glucose. As shown in Figure 1A, comparing with the control at 30-minute time point, 10 $\mu \mathrm{M}$ geniposide treatment significantly increased the phosphorylated level of AMPK protein to $3.39 \pm 0.42$ folds $(\mathrm{p}<0.01)$ in the presence of $5.5 \mathrm{mM}$ glucose. But in the presence of $33 \mathrm{mM}$ glucose, after a shortterm increasing, geniposide suppressed the phosphorylation of AMPK distinctively. As shown in Figure 2B, comparing with the control at
A
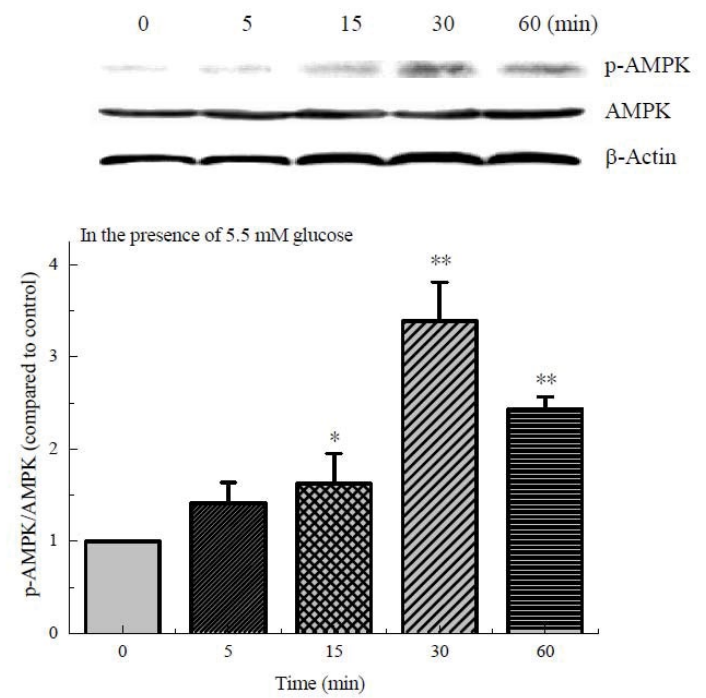

B
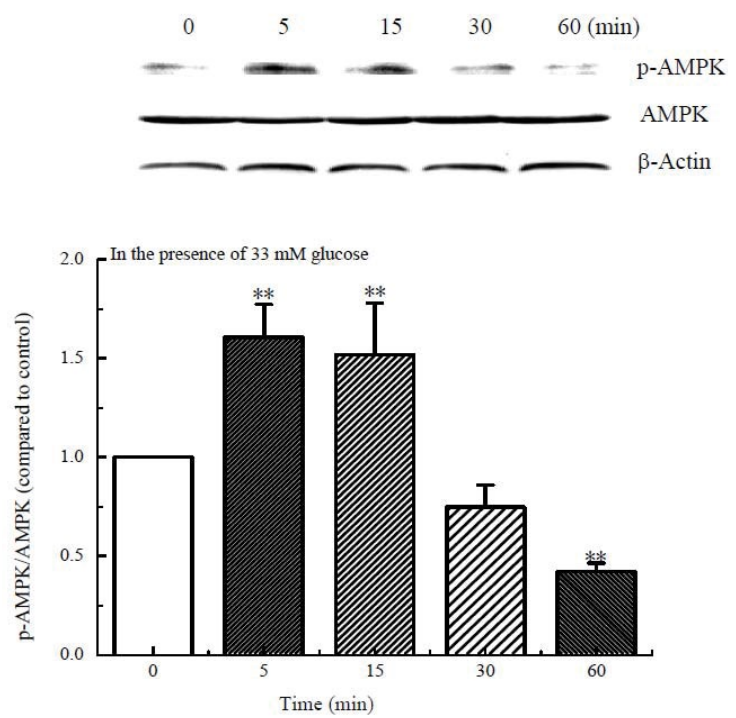

Figure 1: Effects of geniposide on the phosphorylation of AMPK in presence of $5.5(A)$ or 33 (B) mM glucose in INS-1 cells. After INS-1 cells were treated with $10 \mu \mathrm{M}$ geniposide for indicated times, the cells were washed once with PBS, and equal lysates were separated with SDS-PAGE. The phosphorylation of AMPK was probed with western blotting. Data are shown as mean \pm SD from three independent experiments. ${ }^{*} P<0.05$, ${ }^{* *} P<0.01$ vs vehicle. 
60-minute time point, the phosphorylated level of AMPk decreased to $42 \%$ in geniposide-treated INS-1 cells $(\mathrm{p}<0.01)$.

Similarly, the level of SIRT1 was significantly increased to $2.32 \pm$ 0.25 folds $(\mathrm{p}<0.01)$ in cells treated with $10 \mu \mathrm{M}$ geniposide comparing with the control (Figure 2A). But in the presence of $33 \mathrm{mM}$ glucose, geniposide dramatically inhibited the expression of SIRT1. As shown in Figure 2B, comparing with the control at 24-hour time point, treatment with $10 \mu \mathrm{M}$ geniposide decreased the protein level of SIRT1 to $40 \%$ $(\mathrm{p}<0.01)$.

\section{Interaction of AMPK and SIRT1 in geniposide-treating INS- 1 cells}

To explore the interaction of AMPK and SIRT1, we firstly determined the effect of Compound C (an AMPK inhibitor) on the expression of SIRT1, as shown in Figure 3, we observed that, after treatment with 10 $\mu \mathrm{M}$ geniposide for 24 hours, the protein level of SIRT1 was increased to $1.68 \pm 0.21$ folds in the presence of $5.5 \mathrm{mM}$ glucose $(\mathrm{p}<0.05)$, but in the presence of $33 \mathrm{mM}$ glucose, the expression level of SIRT1 was inhibited to about $62 \%$ compared to the control. Furthermore, preincubation with $50 \mu \mathrm{M}$ Compound $\mathrm{C}$, an AMPK inhibitor, decreased the expression of SIRT1 induced by geniposide both in the presence of 5.5 and $33 \mathrm{mM}$ glucose in INS-1 cells.

At the same time, we also measured the influence of Ex 527, a potent and selective inhibitor of SIRT1, on the phosphorylation of AMPK, the results suggested that treatment with Ex 527 significantly inhibited the phosphorylation of AMPK induced by geniposide both in the presence of 5.5 and $33 \mathrm{mM}$ glucose in INS- 1 cells (Figures $4 \mathrm{~A}$ and $4 \mathrm{~B}$ ).

\section{Effect of AMPK/SIRT1 on geniposide regulating glucose uptake and intracellular ATP level}

Mounting evidence show that glucose uptake and ATP content play a critical role on GSIS [1]. Our previous data suggested that geniposide regulating GSIS were associated with its role on glucose uptake and metabolism [17]. To further probe the mechanisms of geniposide regulating GSIS, we determined the influence of Compound C and Ex 527 on the uptake and metabolism of glucose in geniposide-treating INS-1 cells, the results revealed that, similar with our previous work, geniposide accerlated the uptake and metabolism of glucose in the presence of $5.5 \mathrm{mM}$ glucose, but exerted a contrary role on that in the presence of $33 \mathrm{mM}$ glucose. Furthermore, both Compound C and Ex 527 could suppress the effect of geniposide on glucose uptake (Figure $5 \mathrm{~A}$ ) and the production of ATP (Figure 5B) induced by geniposide both in the presence of 5.5 and $33 \mathrm{mM}$ glucose in INS-1 cells.

\section{Discussion}

Hyperinsulinemia, which is a condition in which there are excess levels of insulin circulating in the blood than expected relative to the level of glucose, is associated with hypertension, obesity, dyslipidemia, and glucose intolerance, and often seen in people with early stage type 2 diabetes mellitus [22]. Recently Lamontagne et al. reported troglitazone exerted a direct action on $\beta$ cell to reduce insulin secretion in vitro as pioglitazone [23]. At present, it has been popularly accepted that hyperinsulinemia can cause over insulin secretion and insulin resistance and that lowering insulin secretion in hyperinsulinemic individuals may be beneficial [24].

In our previous study, we reported that geniposide exerted a contrary role on GSIS in the presence of low and very high (over $25 \mathrm{mM}$ ) concentrations of glucose by regulating the level of pyruvate carboxylase, a critical enzyme associated with the metabolism of glucose $[16,17,25]$, which suggests that geniposide might be a promising agent to prevent or delay hyperinsulinemia or glucotoxicity under high glucose burden. But unfortunately, the mechanisms of geniposide regulating the uptake and metabolism of glucose need to be further clarified.

AMPK is a major cellular energy sensor and a master regulator of metabolic homeostasis in eukaryotes that maintains energy stores and enhances aerobic metabolism [7]. A large number of physiological processes have been shown to stimulate AMPK, including conditions that lead to alterations of the ATP/AMP ratio and calcium concentrations, which regulates lipid and glucose metabolism through
A
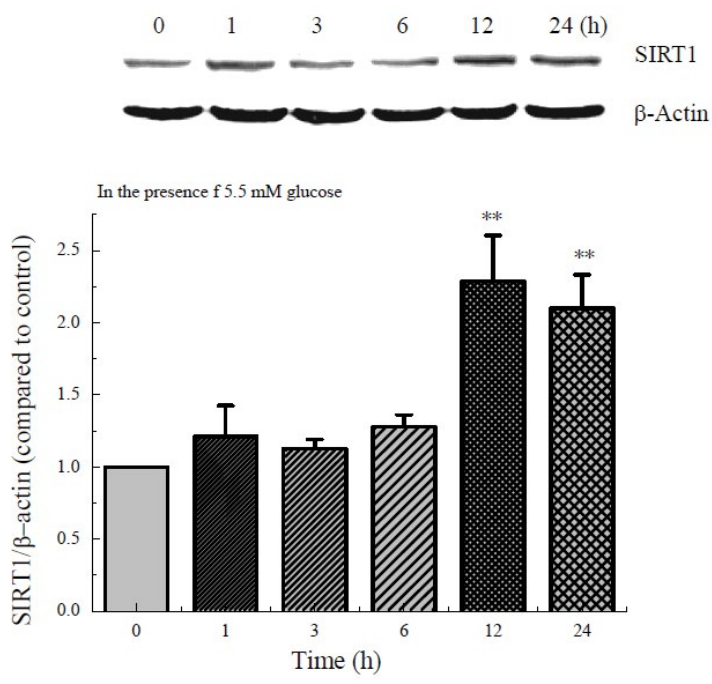

B
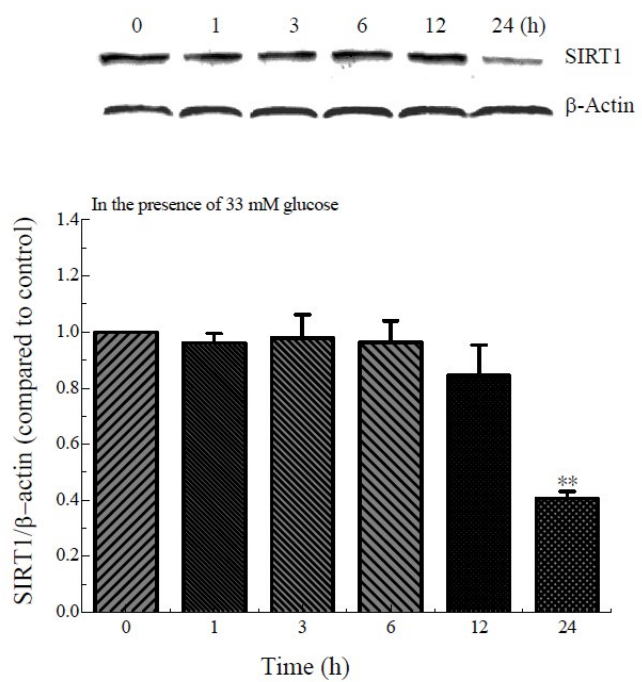

Figure 2: Geniposide regulated the expression of SIRT1 in the presence of low and high concentration of glucose in INS-1 cells. A: Treatment with $10 \mu \mathrm{M}$ geniposide increases the protein levels of SIRT1 in response to $5.5 \mathrm{mM}$ of glucose in INS-1 cells, ${ }^{* *} \mathrm{P}<0.01$ vs vehicle. B: Treatment with $10 \mu \mathrm{M}$ geniposide decreases the protein levels of SIRT1 in response to $33 \mathrm{mM}$ of glucose in INS-1 cells, ${ }^{*} \mathrm{P}<0.01$ vs vehicle. Data are means \pm SD from at least three independent experiments. 
A

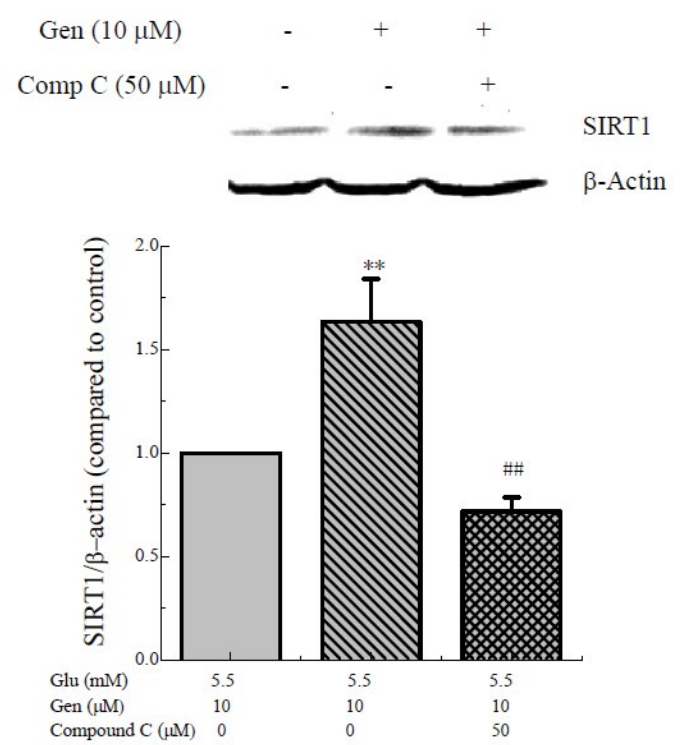

B

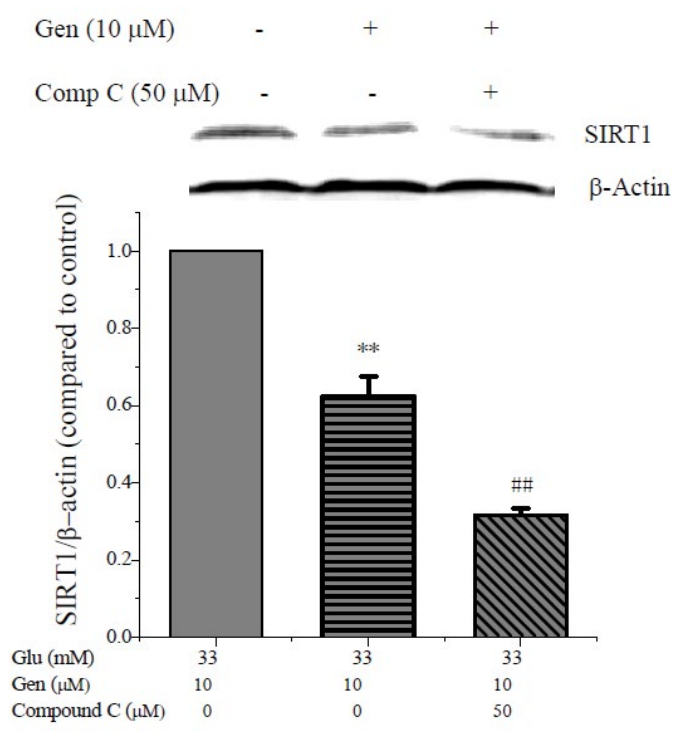

Figure 3: Effects of Compound $C$ on the expression of SIRT1 in presence of $5.5(A)$ or $33(B)$ mM glucose in INS-1 cells. After INS-1 cells were treated with 50 $\mu \mathrm{M}$ Compound C, a specific inhibitor for AMPK for $30 \mathrm{~min}, 10 \mu \mathrm{M}$ geniposide was added into the INS-1 cells and continued to culture for $24 \mathrm{~h}$. After that, the cells were washed once with PBS, and equal lysates were separated with SDS-PAGE. The expression of SIRT1 was probed with western blotting. Data are shown as mean \pm SD from three independent experiments. ${ }^{*} \mathrm{P}<0.01$ vs control, and ${ }^{\#} \mathrm{P}<0.01$ vs the group of geniposide alone.

A

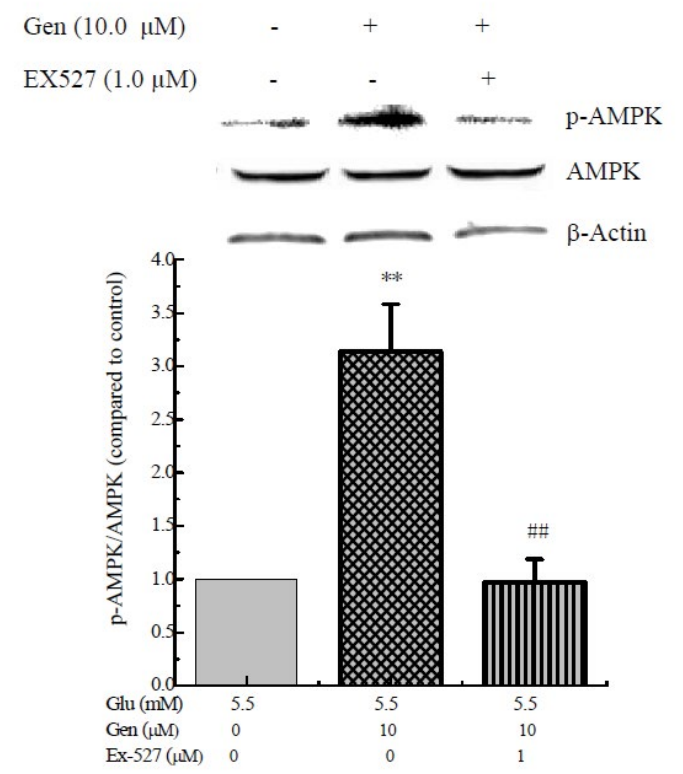

B

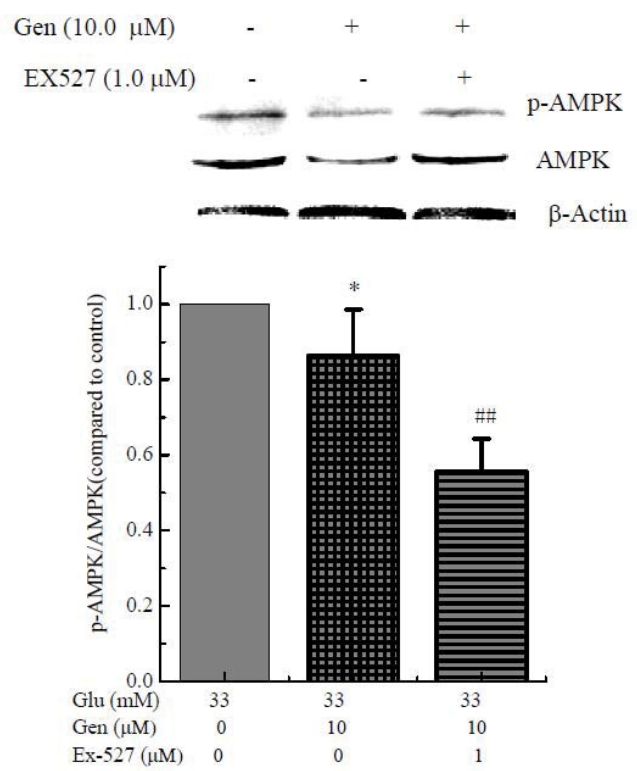

Figure 4: Effects of Ex 527 on the phosphorylation of AMPK in presence of 5.5 (A) or 33 (B) mM glucose in INS-1 cells. After INS-1 cells were treated with 1 $\mu \mathrm{M}$ Ex 527, a specific inhibitor for SIRT1 for $30 \mathrm{~min}, 10 \mu \mathrm{M}$ geniposide was added into the INS-1 cells and continued to culture for 60 min. After that, the cells were washed once with PBS, and equal lysates were separated with SDS-PAGE. The phosphorylation of AMPK was probed with western blotting. Data are shown as mean \pm SD from three independent experiments. ${ }^{*} \mathrm{P}<0.05,{ }^{* *} \mathrm{P}<0.01$ vs control, and ${ }^{\# \prime} \mathrm{P}<0.01$ vs the group of geniposide alone.

direct phosphorylation of its substrates [5]. In this study, we found that geniposide could regulate the phosphorylation AMPK both in the presence of low $(5.5 \mathrm{mM})$ and very high $(33 \mathrm{mM})$ concentrations of glucose in INS-1, a pancreatic $\beta$ cells. Furthermore, as shown in Figure 5, pre-incubation with Compound C, an AMPK inhibitor, prevented the effects of geniposide on the uptake of glucose and intracellular ATP production, which is a key driving factor for insulin release, in INS-1 cells.

Additionally, because SIRT1, an NAD-dependent deacetylase, that acts as a master metabolic sensor of $\mathrm{NAD}^{+}$, played an important role in mitochondrial biogenesis and glucose homeostasis [6,7]. We also 
A

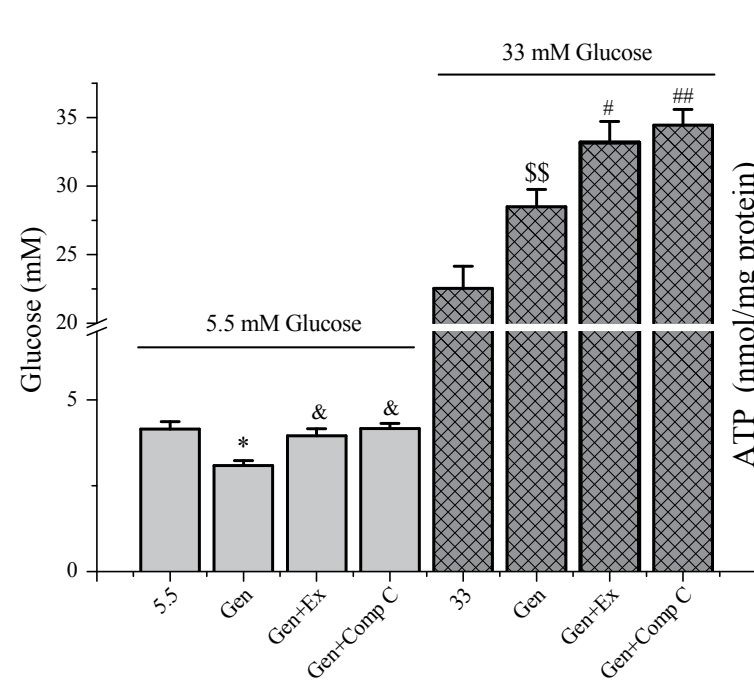

B

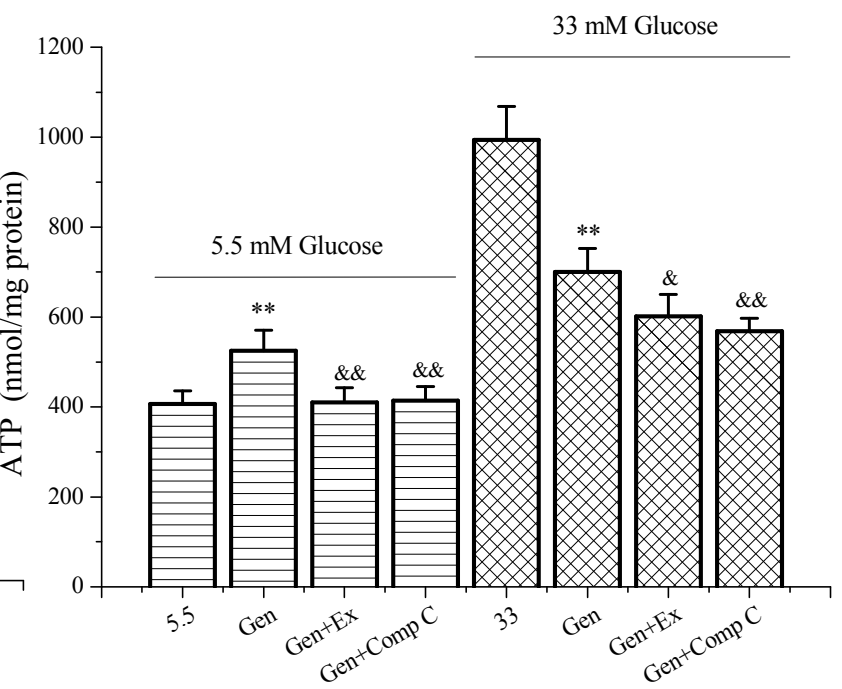

Figure 5: Effects of AMPK/ SIRT1 on geniposide regulating glucose uptake (A) and ATP level (B). INS-1 cells were seeded onto 6-well plate. After overnight incubation, the cells were washed once with KRBB and starved for 2 hours in KRBH buffer. Then, Compound C or Ex 527 incubated for 30 min respectively before starved for 20 minutes in the presence or absence of $10 \mu \mathrm{M}$ geniposide with KRBB containing 5.5 or 33 mM of glucose. After 20 minutes of incubation, glucose concentration in the buffer was measured and the uptake of glucose was determined by the difference of glucose concentrations in the buffer after incubation relative to pre-incubation. The intracellular content of ATP was measure in cell lysates using ATP bioluminescence assay kits according to the manufacturer's instructions. Data are means \pm SD from three representative experiments $(n=3$, three wells for each replicate). " $P<0.05$, * $P<0.01$ vs the same glucose concentrations without geniposide. ${ }^{\&} \mathrm{P}<0.05$, ${ }^{\&} \mathrm{P}<0.01$ vs the same glucose concentrations with geniposide.

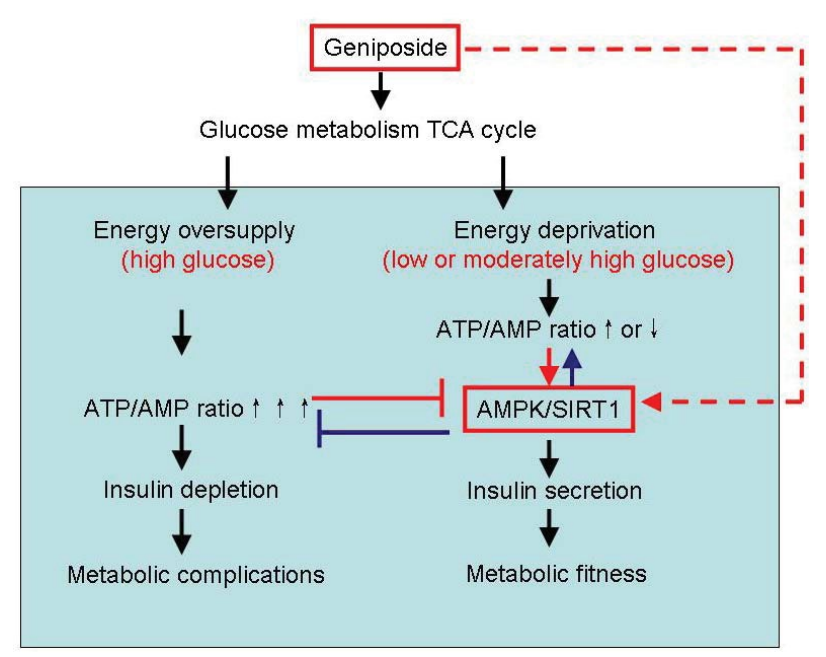

Figure 6: A sketch of geniposide adjusting the metabolic network of energy expenditure.

determined the effects of geniposide on the expression of SIRT1 in INS1 cells. The results showed that geniposide could regulate the expression of SIRT1 in the presence of low $(5.5 \mathrm{mM})$ and very high $(33 \mathrm{mM})$ concentrations of glucose. Moreover, unlike the sustained activation in presence of $5.5 \mathrm{mM}$ glucose, p-AMPK was fleetly decreased in the presence of $33 \mathrm{mM}$ glucose, and SIRT1 expression also showed the same trend. All these observations revealed that AMPK/SIRT1, as the central regulators of cellular metabolism, were intimately linked with energy balance regulated by geniposide in presence of different concentrations of glucoses.

Furthermore, to analyze the interaction of AMPK and SIRT1 during the process of geniposide regulating glucose uptake and metabolism, Ex527 and Compound C were used in this study, the results demonstrated that Ex527 could prevent the role of geniposide on the phosphorylation of AMPK, and Compound C could prohibit the expression of SIRT1 induced by geniposide both in the presence of low and very high concentrations of glucose in INS-1 cells. So we have observed a close correlation between AMPK phosphorylation and SIRT1 level, indicating that the persistently increased the phosphorylations of AMPK and the expression of SIRT1 by geniposide in response to low glucose indicates a sequence of events in which geniposide increased the phosphorylation AMPK and the expression of SIRT1, accelerated the uptake and metabolism of glucose, promoted the production of ATP, and ultimately improved insulin secretion in pancreatic $\beta$ cells, but when the cells challenged by very high concentrations of glucose, geniposide exerted a contrary role. The possible way of geniposide regulating energy balance in INS-1 cells was summarized in Figure 6.

Collectively, the data presented here provide novel and in-depth evidence for the role of geniposide on pancreatic $\beta$-cells glucose and energy homeostasis. Due to the capacity of geniposide to preserve pancreatic $\beta$-cells from exhaustion resulted from prolonged and over insulin secretion under high glucose burden [17], geniposide might be used as a novel small molecular for the treatment of hyperinsulinemia, and delayedthe developmental progress of type 2 diabetes.

\section{Acknowledgements}

This work was supported by grants from Natural Science Foundation of China (81373459), Innovation of Science and Technology Leading Talent in Chongqing (CSTC2014kjcxljrc0009), Chongqing Natural Science Foundation (CSTC, 2014jcyjA10048), Innovative Research Team Development Program at the University of Chongqing (No KJTD201314), the Natural Science Startup Foundation of Chongqing Technology and Business University (1352009) and the open project of Key Laboratory of Natural Medicine Research of Chongqing Education Commission (1456032, CQCM-2015-08).

\section{References}

1. Winder WW, Hardie DG (1999) AMP-activated protein kinase, a metabolic master switch: possible roles in type 2 diabetes. Am J Physiol 277: E1-10. 
Citation: Guo L, Liu C, Yin F, Liu J (2016) Possible Role of AMPK/SIRT1 Signaling on Energy Balance in Geniposide-Treated INS-1 Cells. Med chem 6: 033-038. doi:10.4172/2161-0444.1000319

2. O'Neill HM (2013) AMPK and Exercise: Glucose Uptake and Insulin Sensitivity. Diabetes Metab J 37: 1-21.

3. Kemp BE, Stapleton D, Campbell DJ, Chen ZP, Murthy S, et al. (2003) AMPactivated protein kinase, super metabolic regulator. Biochem Soc Trans 31: 162-168.

4. Marsin AS, Bertrand L, Rider MH, Deprez J, Beauloye C, et al. (2000) Phosphorylation and activation of heart PFK-2 by AMPK has a role in the stimulation of glycolysis during ischaemia. Curr Biol 10: 1247-1255.

5. Viollet B, Andreelli F, Jørgensen SB, Perrin C, Flamez D, et al. (2003) Physiological role of AMP-activated protein kinase (AMPK): insights from knockout mouse models. Biochem Soc Trans 31: 216-219.

6. Canto C, Auwerx J (2009) PGC-1alpha, SIRT1 and AMPK, an energy sensing network that controls energy expenditure. Curr Opin Lipidol 20: 98-105.

7. Canto C, Gerhart-Hines Z, Feige JN, Lagouge M, Noriega L, et al. (2009) AMPK regulates energy expenditure by modulating $\mathrm{NAD}^{+}$metabolism and SIRT1 activity. Nature 458: 1056-1060.

8. Fulco M, Cen Y, Zhao P, Hoffman EP, McBurney MW, et al. (2008) Glucose restriction inhibits skeletal myoblast differentiation by activating SIRT1 through AMPK-mediated regulation of Nampt. Dev Cell 14: 661-673.

9. Yang T, Fu M, Pestell R, Sauve AA (2006) SIRT1 and endocrine signaling. Trends Endocrinol Metab 17: 186-191.

10. Potente M, Dimmeler S (2008) Emerging roles of SIRT1 in vascular endothelial homeostasis. Cell Cycle 7: 2117-2122.

11. Li H, Min Q, Ouyang C, Lee J, He C, et al. (2014) AMPK activation prevents excess nutrient-induced hepatic lipid accumulation by inhibiting mTORC1 signaling and endoplasmic reticulum stress response. Biochim Biophys Acta 1842: $1844-1854$.

12. Herms A, Bosch M, Reddy BJ, Schieber NL, Fajardo A, et al. (2015) AMPK activation promotes lipid droplet dispersion on detyrosinated microtubules to increase mitochondrial fatty acid oxidation. Nat Commun 6: 7176.

13. Kim WH, Lee JW, Suh YH, Lee HJ, Lee SH, et al. (2007) AICAR potentiates ROS production induced by chronic high glucose: roles of AMPK in pancreatic beta-cell apoptosis. Cell Signal 19: 791-805.

14. Iglesias MA, Ye JM, Frangioudakis G, Saha AK, Tomas E, et al. (2002) AICAR administration causes an apparent enhancement of muscle and liver insulin action in insulin-resistant high-fat-fed rats. Diabetes 51: 2886-2894.
15. Song XM, Fiedler M, Galuska D, Ryder JW, Fernström M, et al. (2002) 5-Aminoimidazole-4-carboxamide ribonucleoside treatment improves glucose homeostasis in insulin-resistant diabetic (ob/ob) mice. Diabetologia 45: 56-65.

16. Guo LX, Xia ZN, Gao X, Yin F, Liu JH (2012) Glucagon-like peptide 1 receptor plays a critical role in geniposide-regulated insulin secretion in INS-1 cells. Acta Pharmacol Sin 33: 237-241.

17. Liu J, Guo L, Yin F, Zhang Y, Liu Z, et al. (2013) Geniposide regulates glucosestimulated insulin secretion possibly through controlling glucose metabolism in INS-1 cells. PLoS One 8: e78315.

18. Burmeister MA, Ayala J, Drucker DJ, Ayala JE (2013) Central glucagon-like peptide 1 receptor-induced anorexia requires glucose metabolism-mediated suppression of AMPK and is impaired by central fructose. Am J Physiol Endocrinol Metab 304: E677- E685.

19. Ha J, Guan KL, Kim J (2015) AMPK and autophagy in glucose/glycogen metabolism. Mol Aspects Med 46: 46-62.

20. Min Z, Linna X, Yaoji L, Suqin W, Huijuan X, et al. (2015) Recognition of cytosolic DNA attenuates glucose metabolism and induces AMPK mediated energy stress response. Int J Biol Sci 11: 587-594.

21. Liu JH, Yin F, Guo LX, Deng XH, Hu YH (2009) Neuroprotection of geniposide against hydrogen peroxide induced $\mathrm{PC} 12$ cells injury: involvement of $\mathrm{PI} 3$ kinase signal pathway. Acta Pharmacol Sin 30: 159-165.

22. Modan M, Halkin H, Almog S, Lusky A, Eshkol A, et al. (1985) Hyperinsulinemia A link between hypertension obesity and glucose intolerance. J Clin Invest 75 : 809-817.

23. Lamontagne J, Pepin E, Peyot ML, Joly E, Ruderman NB, et al. (2009) Pioglitazone acutely reduces insulin secretion and causes metabolic deceleration of the pancreatic beta-cell at submaximal glucose concentrations. Endocrinology 150: 3465-3474.

24. Gonzalez A, Merino B, Marroquí L, Ñeco P, Alonso-Magdalena P, et al. (2013) Insulin hypersecretion in islets from diet-induced hyperinsulinemic obese female mice is associated with several functional adaptations in individual betacells. Endocrinology 154: 3515-3524.

25. Guo LX, Liu JH, Yin F (2014) Regulation of insulin secretion by geniposide: possible involvement of phosphatidylinositol 3-phosphate kinase. Eur Rev Med Pharmacol Sci 18: 1287-1294. 